\title{
EARLY-AGE AUTOGENOUS CRACKING OF CEMENT- BASED SYSTEMS: FROM PHYSICO-CHEMICAL ANALYSIS TO MICRO/MACRO INVESTIGATIONS
}

\author{
P. Mounanga ${ }^{a}$, M. Bouasker, A. Pertué, A. Perronnet, and A. Khelidj \\ GeM, UMR CNRS 6183 - Research Institute on Civil Engineering and Mechanics, University of \\ Nantes - IUT Saint-Nazaire, 58 rue Michel Ange, BP 420,F-44606 Saint-Nazaire cedex, France
}

\begin{abstract}
High-performance cement-based materials, characterized by a low water-tocement $(\mathrm{W} / \mathrm{C})$ ratio and a high cement content, are particularly sensitive to early-age cracking because the magnitude and the rate of autogenous shrinkage they develop during this period, are particularly high. This article presents a parametric study carried out in order to quantify the influence of W/C ratio, cement type, curing temperature and aggregates content on the evolution of physico-chemical deformations and the early-age cracking risk they can generate.
\end{abstract}

\section{Introduction}

During setting and hardening, cementitious matrices exhibit important volume variations due to their thermal, hygral and physico-chemical evolution [1, 2]. Among these deformations, autogenous shrinkage and thermal deformations are particularly problematic for the durability of concretes with a low water-to-cement ratio. Indeed, high cement content considerably increases the magnitude of these deformations at early age, inducing a risk of premature cracking [3].

Autogenous shrinkage corresponds to the matrix strain measured at constant temperature. Its physico-chemical origins result from chemo-mechanical and hygro-mechanical interactions within the hardening cementitious matrix.

The chemo-mechanical deformations develop since the first contact between the anhydrous binder and mixing water. This chemical shrinkage (also known as Le Chatelier's contraction) is explained by the negative balance between the absolute density of hydrates and those of cement and water.

The hygro-mechanical autogenous deformations take place during and beyond the setting period. They result from the development of internal tensile stresses within the matrix. At early age, these self-induced stresses are generated by the capillary tension created by the water consumption due to hydration. The consecutive deformation is called self-desiccation shrinkage. In restrained conditions, internal self-induced stresses are likely to involve a premature cracking when they become higher than the tensile strength of the matrix. The prediction of this cracking requires a better understanding of the phenomena involved.

\footnotetext{
a e-mail : pierre.mounanga@univ-nantes.fr
} 
This study is a contribution to the better understanding of autogenous early-age cracking in cementitious matrices, considering two levels of investigation:

1) The deformations of the material are studied since the very early age (a few minutes after the end of mixing) until the moment of potential early-age cracking

2) The cracks generated by these deformations are analyzed at a macroscopic level, focusing on through crack in cement paste, and at a microscopic level, highligthing the microcracks developing in the interfacial zone between cement paste and aggregate.

In this paper, some metrological aspects about the measurement of autogenous strain are presented, before analyzing the effects of the cement paste composition, curing temperature and presence of aggregates on chemical and autogenous shrinkage at early ages.

\section{Materials and mixtures}

Three cements have been studied: a CEM I 52.5 N Portland cement (noted CEM I), and two blended cements, one with $24 \%$ of limestone filler (CEM II 32.5 R, noted CEM II), and the other containing $62 \%$ of blast furnace slag (CEM III/A $42.5 \mathrm{~N}$, noted CEM III).

The sand used for the preparation of mortars is a $0 / 2-\mathrm{mm}$ standardized siliceous sand from Leucate plant, France (EN 196-1). Its absolute density is $2650 \mathrm{~kg} / \mathrm{m}^{3}$. Before use, the sand was dried in a $40^{\circ} \mathrm{C}$-oven, for 24 hours, and cooled in a desiccator for 5 hours.

Cement pastes and mortars were manufactured by mixing the solid components with tap water, during 3 minutes. The 5-L mortar mixer used is in conformity with EN 196-1 standard [4]. In this study, 6 cement pastes and 9 mortars of different compositions were studied. The formulas were selected in order to investigate the influence of mix parameters such as the water-to-cement ratio $(\mathrm{W} / \mathrm{C}=0.30$ and 0.40$)$, the type of cement (CEM I, CEM II and CEM III), and the sand-to-cement ratio $(\mathrm{S} / \mathrm{C}=0,1$ and 2$)$. For the tests in restrained conditions, different curing temperatures were also considered $\left(\mathrm{T}=10,20,30\right.$ and $\left.40^{\circ} \mathrm{C}\right)$.

\section{Testing methods}

The differents experimental methods used are recapitulated in Table 1.

The setting times of cement pastes have been measured at $20^{\circ} \mathrm{C}$ through Vicat needle penetration tests, with an accuracy of $\pm 10 \mathrm{~min}$ [5]. The amount of chemically-bound water was determined by the loss-on-ignition method, recorded between 145 and $950{ }^{\circ} \mathrm{C}$. The dynamic Young's modulus was measured via impulse excitation tests with a Grindosonic $\AA$ device on $4 \times 4 \times 16-\mathrm{cm}^{3}$ prismatic specimens [6]. The interfacial zone (ITZ) between cement paste and sand grains were studied by Scanning Electronic Microscopy (SEM) in secondary mode.The samples were previously dried at $40^{\circ} \mathrm{C}$ and impregnated with an epoxy resin. The samples were then polished and covered with a 200$\AA$ layer of palladium gold before introduction in the SEM chamber [6]. Details about the methods used for the measurements of chemical and autogenous deformations in free and restrained conditions can be found in [7-9].

Table 1. Properties measured and testing methods used on cement pastes and mortars.

\begin{tabular}{|c|c|c|}
\hline Properties & Experimental methods & References \\
\hline Setting times & Vicat needle tests & {$[5]$} \\
\hline Chemically-bound water & Loss-on-ignition method between 145 and $950^{\circ} \mathrm{C}$ & {$[6]$} \\
\hline Dynamic elastic modulus & Impulse excitation tests on $4 \times 4 \times 16-\mathrm{cm}^{3}$ specimens & {$[6]$} \\
\hline ITZ microstructure & SEM observations & {$[6]$} \\
\hline Chemical shrinkage & Hydrostatic weighing & {$[7]$} \\
\hline Free autogenous shrinkage & Vertical lineic and volumetric tests & {$[8]$} \\
\hline $\begin{array}{c}\text { Restrained autogenous } \\
\text { shrinkage }\end{array}$ & Quasi-isothermal ring test & {$[9]$} \\
\hline
\end{tabular}




\section{Results and analysis}

\subsection{Physico-chemical evolution and chemical shrinkage}

\subsubsection{Effects of the cement paste composition}

Figure 1 provides the evolution of chemical shrinkage as a function of the age of the six studied cement pastes. The $\mathrm{W} / \mathrm{C}$ ratio has a relatively weak influence on the value of the chemical shrinkage obtained at $72 \mathrm{~h}$. The effect of this parameter is sensitive over the very first hours: a weaker W/C ratio induces a faster rate of chemical shrinkage. This effect can be explained by a faster precipitation of the hydration products in more concentrated media [7]. During the first $24 \mathrm{~h}$ of hydration, the concentration effect loses its influence, and the pastes with a higher W/C ratio show a faster development of the chemical shrinkage. This higher chemical shrinkage rate is related to the supplementary water available for the hydration of cement. The effect of cement type is more sensitive on the evolution of chemical shrinkage: Figure 1 shows that, during the first hours of hydration, until about $48 \mathrm{~h}$, the CEM I cement exhibits a chemical shrinkage higher than those of the CEM II and CEM III cements. Then, the shrinkage evolution of the CEM III cement significantly accelerates: at $72 \mathrm{~h}$, it reaches values equal and even higher than those of the CEM I cement. Figure 2 shows the evolution of chemical shrinkage vs. the amount of non-evaporable water. For a given quantity of non-evaporable water, the chemical shrinkage of CEM III cement is clearly higher than those of CEM I and CEM II cements. It confirms that the presence of slag in high content influences the morphology and the density of hydrates formed at early and very early ages.

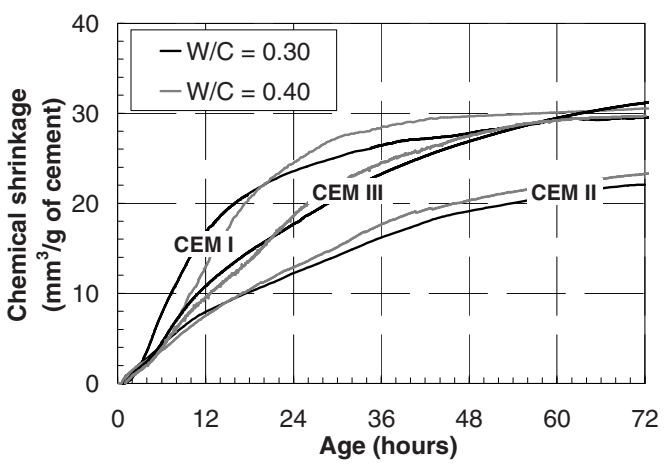

Fig. 1. Chemical shrinkage evolution vs. hydration age of cement pastes.
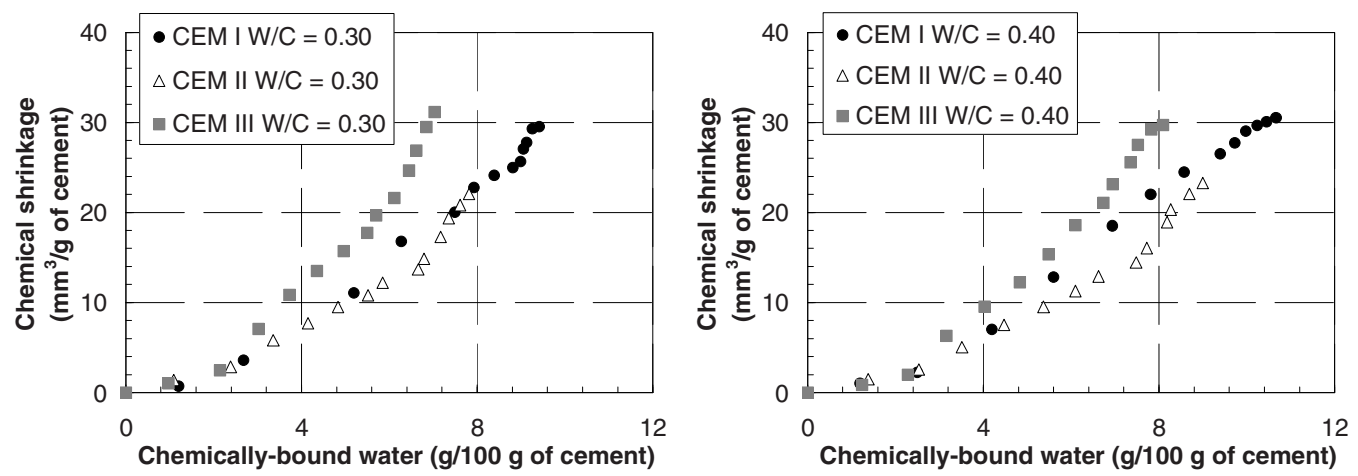

Fig. 2. Chemical shrinkage evolution vs. chemically-bound water; left: $\mathrm{W} / \mathrm{C}=0.30$, right: $\mathrm{W} / \mathrm{C}=0.40$. 


\subsubsection{Effects of the aggregate content}

At least, three mechanisms may explain the influence of aggregates on the evolution of the chemical deformations of cementitious matrices:

- The restraining effect of aggregates, which partially restrains the development of the deformations of the surrounding cement paste.

- The dispersive and abrasive effect. During the mixing, aggregates, by striking and shearing the cement grain clusters, induce a better dispersion and thus a better hydration of the binder [10].

- The effect of site, due to fine aggregate particles $(<100 \mu \mathrm{m})$. These fine particles play the role of additional nucleation and growth sites for hydrates $[10,11]$.

It should be noted that the first effect tends to reduce the cement paste deformations while the two others tend to increase them. Figure 3 shows that the increase in the granular concentration, results in an increase of chemical shrinkage per $g$ of cement. This proves that the effects of dispersion and site of sand grains are dominating, compared to the restraining effect.

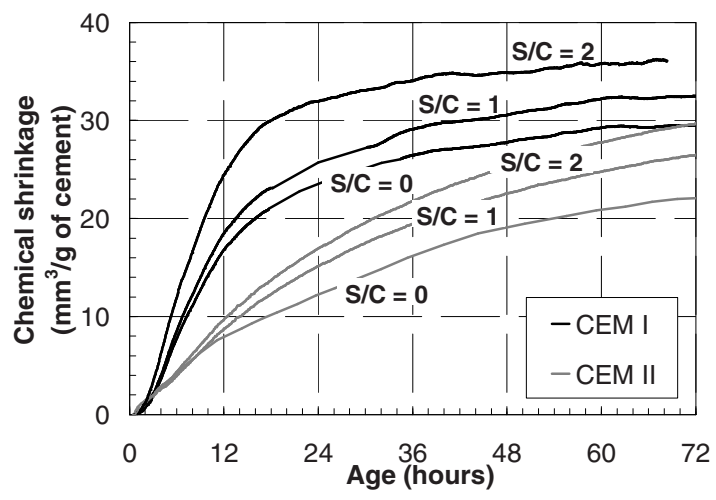

Fig. 3. Effect of the Sand/Cement ratio $(S / C)$ on chemical shrinkage of mortars $(W / C=0.30)$.

\subsection{Free autogenous shrinkage}

\subsubsection{Effects of the cement paste composition}

Figure 4 provides the evolution of autogenous shrinkage of cement pastes with $\mathrm{W} / \mathrm{C}=0.30$. Strain of the three cement pastes is rather close during the first $4 \mathrm{~h}$ of hydration, in accordance with the results obtained on chemical shrinkage at very early age (Figure 1). Beyond these first hours, the curves of the three cements diverge. While the curves of CEM I and CEM II cements flatten, indicating the transition between the period dominated by chemo-mechanical strain and that controlled by hygromechanical deformations, the CEM III cement curve continues to increase quickly.

The flattening of the CEM I and CEM II curves occurs during the setting period, whereas the curve of CEM III cement only flattens several hours later (Figure 4). This extension of the chemomechanical phase results in an increase of the autogenous deformations. Several authors also observed that blast furnace slag generally causes a significant increase in early-age autogenous shrinkage [12-14]. They attribute this phenomenon to higher chemical shrinkage and finer pore distribution of cementitious matrices containing slag [15]. With these two causes, a third mechanical one can be added: the evolution of the mechanical properties, and in particular of Young's modulus, is slower for the matrices containing slag cement; for a given W/C ratio, the Young's modulus of the CEM III cement pastes is always largely lower than that of the CEM I cement pastes (Figure 5.a): submitted to an identical internal capillary tension, the CEM III cement paste will shrink much more than the CEM I cement paste. 


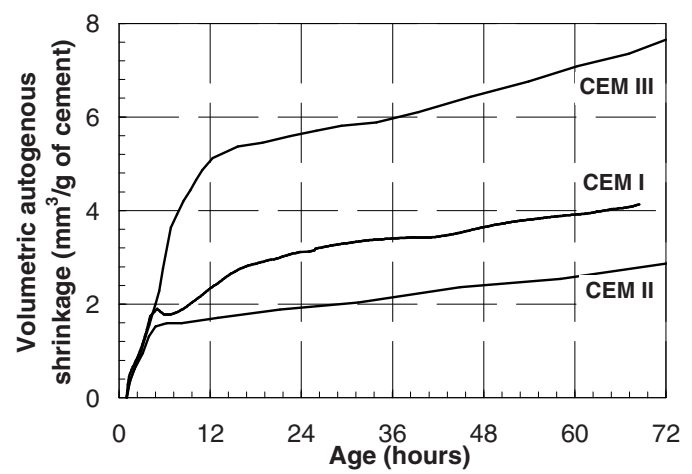

a) From 1 to $72 \mathrm{~h}$

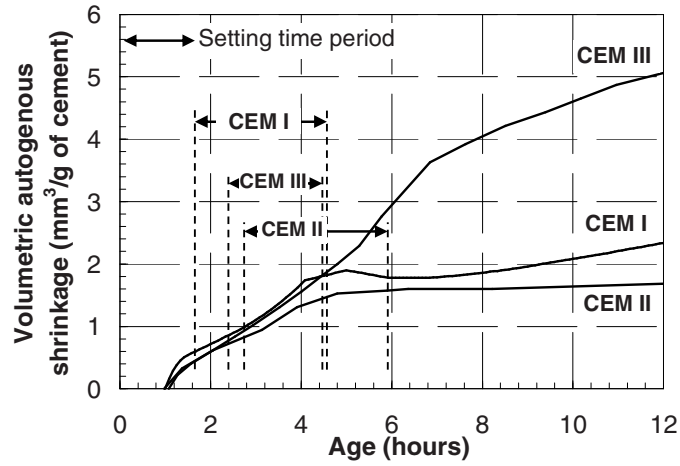

b) From 1 to $12 \mathrm{~h}$

Fig. 4. Autogenous shrinkage of cement pastes with $\mathrm{W} / \mathrm{C}=0.30$.

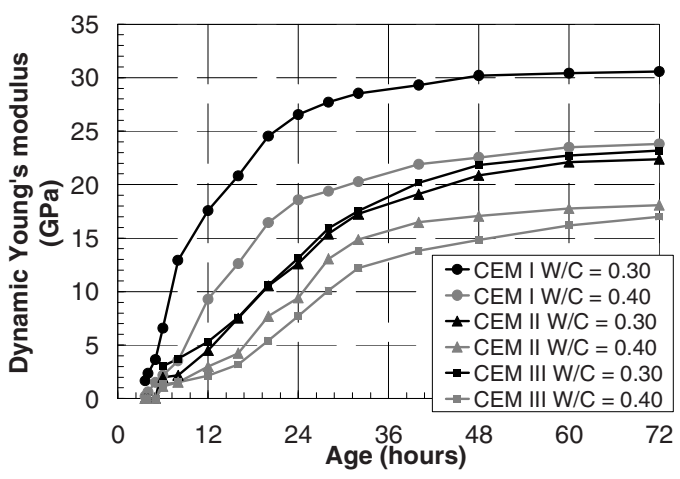

a) Results on different cement pastes

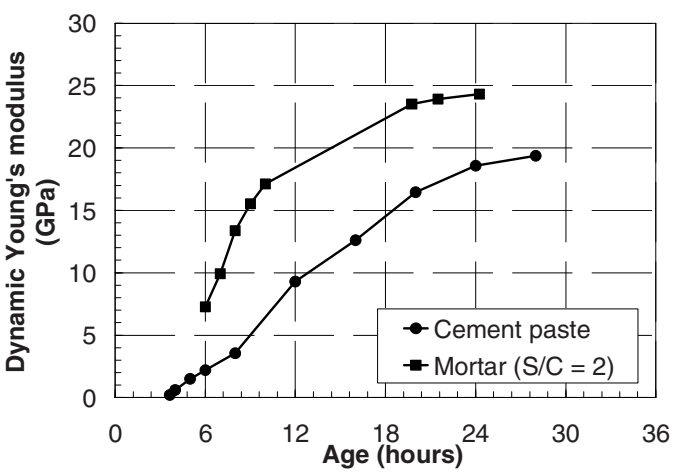

b) Comparison between cement paste and mortar $($ CEM I cement; $\mathrm{W} / \mathrm{C}=0.40)$

Fig. 5. Dynamic Young's modulus of various cement pastes and mortar.

\subsubsection{Effects of the aggregate content}

In general, four potential effects of aggregates on autogenous strain may be distinguished:

- A global mechanical effect on the evolution of Young's modulus i.e. on the capacity of the material to deform under stress (Figure 5.b);

- A local mechanical effect of restraint of the cement paste deformations in the immediate vicinity of the aggregates, which can cause microcracking of the cement paste [16];

- A dilution effect on the self-desiccation of the cement-based matrix;

- An effect of "water tank" [17] related to the water transfer between the aggregates and the paste. During mixing, water can be absorpted by the aggregates. After the setting, the self-desiccation may generate forces allowing a transport of water from aggregates towards the unsaturated pores of the cement paste.

The combination of these four effects results in a decrease of autogenous shrinkage as the S/C ratio increases (Figure 6.a). It is possible to decouple the dilution effect from the mechanical and the "water tank" effects, by expressing the deformations in $\mathrm{mm}^{3}$ per $\mathrm{g}$ of cement: The difference between the curves is then much lower and corresponds to the mechanical and the "water tank" effects of aggregates. The initialization of the deformations at $6 \mathrm{~h}$ of hydration enables to focus on the self-desiccation deformations (Figure 6.b). At the end of the period of investigation, the cement paste shrinkage remains 2 to 4 times superior to the mortar shrinkage.

In order to analyse more deeply these differences, investigations have been carried out at the microscopic scale, through Scanning Electron Microscope (SEM) observations. 


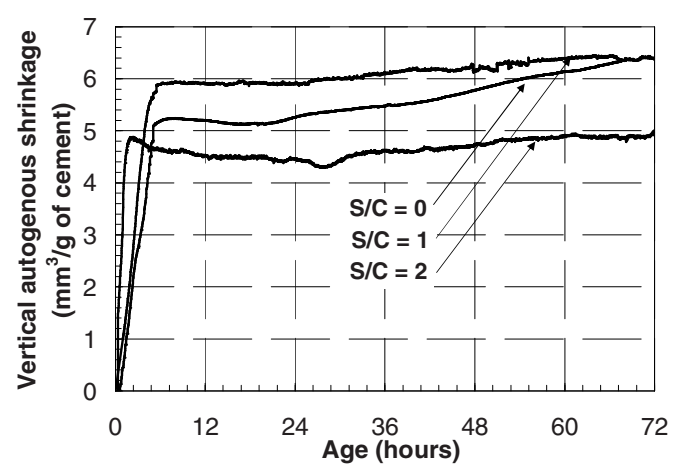

a) Between 0 and $72 \mathrm{~h}$

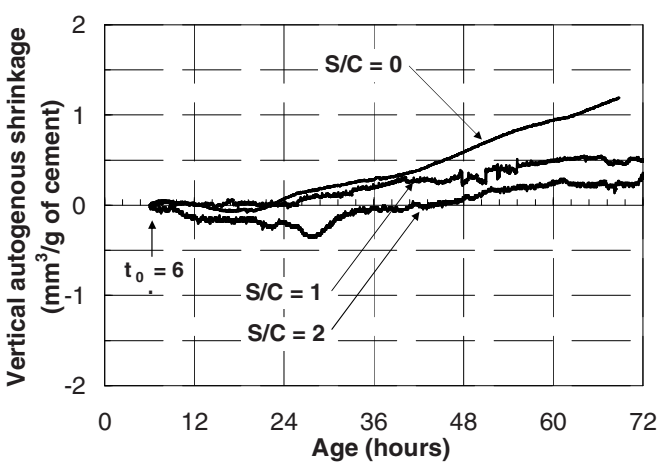

b) Initialized at $6 \mathrm{~h}$

Fig. 6. Effect of the granular concentration on autogenous shrinkage (CEM I cement; W/C = 0.40).

\subsection{Consequences of autogenous deformations}

\subsubsection{Microcracking in the interfacial zone between cement paste and aggregates}

SEM observations in secondary electron dectection mode were performed, focusing on the interfacial zone between cement paste and aggregates.

It is important to specify that the results of the present study are comparative, taking into account the method of sample preparation. Indeed, before observation, each sample is polished in order to obtain a perfectly plane surface. This operation could generate a network of microscopic cracks or a separation between aggregates and cement paste. In order to decouple the effect of the sample treatment from the aggregate effect on the development of microscopic cracks, a test was carried out on CEM I cement paste (without aggregates) following the same protocol. On this cement paste sample, no microscopic cracks were detected. One can thus reasonably suppose that the appearance of microscopic cracks observed in mortar is mainly related to the restraining effect of aggregates on the cement paste autogenous shrinkage.

Typical SEM observations on mortar are shown in Figure 7. At the scale of measurement considered, and for the W/C ratio investigated, these observations revealed the absence of a transition zone between the cement paste and the aggregates during the first four days of hydration, in agreement with previous work [18]. However, a network of microscopic cracks is observed (Figure 7). SEM observations, made at different hydration ages, show that there is an evolution of the microstructure at the interface between cement paste and aggregate. At the age of $10 \mathrm{~h}$, very fine cracks, with a thickness of about 0.1 to 0.3 micron, appear. These cracks are generally isolated, without interconnection. At $48 \mathrm{~h}$ of hydration, the microstructure is denser and a clearer network of microscopic cracks, with a thickness varying from 0.1 to 0.8 micron, develops. Finally, at $96 \mathrm{~h}$ of hydration, the density of cracks becomes higher (Figure 7.c).

The presence of these microcracks can partially explain the difference in shrinkage (in $\mathrm{mm}^{3}$ per $\mathrm{g}$ of cement) observed between cement paste and mortar prepared with the same $\mathrm{W} / \mathrm{C}$ ratio (Figure 6.a): indeed, the microscopic cracks tend to "dilate" the sample by increasing the internal porosity of material, thus reducing the magnitude of the measured autogenous shrinkage. 


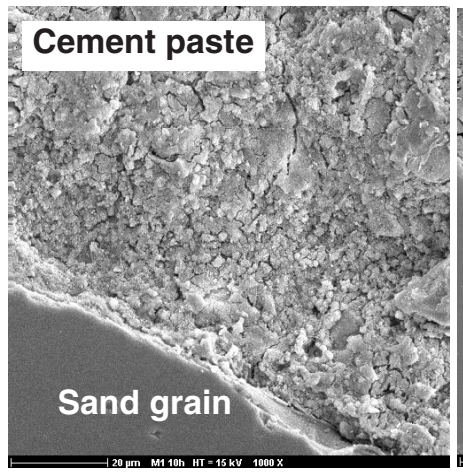

a) $10 \mathrm{~h}$ of hydration

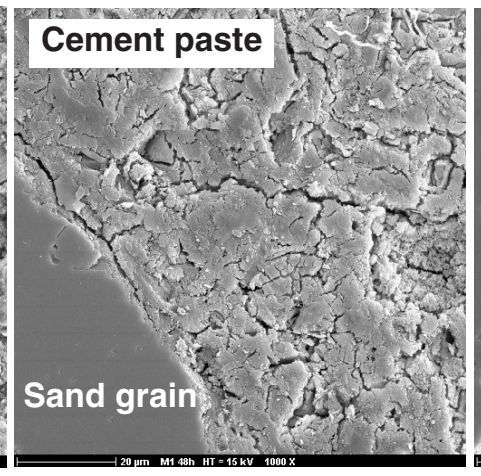

b) $48 \mathrm{~h}$ of hydration

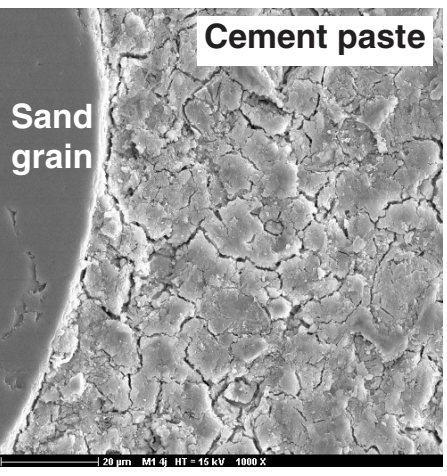

c) $96 \mathrm{~h}$ of hydration

Fig. 7. SEM observations of CEM I-cement mortar with $\mathrm{W} / \mathrm{C}=0.30$ and $\mathrm{S} / \mathrm{C}=1$.

\subsubsection{Early-age through cracks in cement paste}

Restrained autogenous shrinkage can also induce visible through cracks in cement-based materials. These trough cracks are particulary detrimental to the durability of the material.

Typical curves of restrained autogenous deformations measured with ring tests are presented in Figure 8.a. The increase in temperature causes a reduction in the cracking age, as shown in Figure 8.b. This acceleration of cracking is a direct consequence of the thermoactivation of the early-age hydration reactions; with higher temperature, the self-desiccation, the consecutive autogenous shrinkage and Young's modulus develop more quickly and induce an increase of the internal stress rate.

The first through crack appears earlier in the cementitious matrix with lower W/C ratio (Figure 8). Indeed, the reduction of the initial water amount results in more intense autogenous deformations [19] and higher Young's modulus (Figure 5.a) at early age, leading to earlier autogenous cracking. The CEM III cement also leads to earlier cracking: this could be explained by the higher autogenous shrinkage of this type of cement.

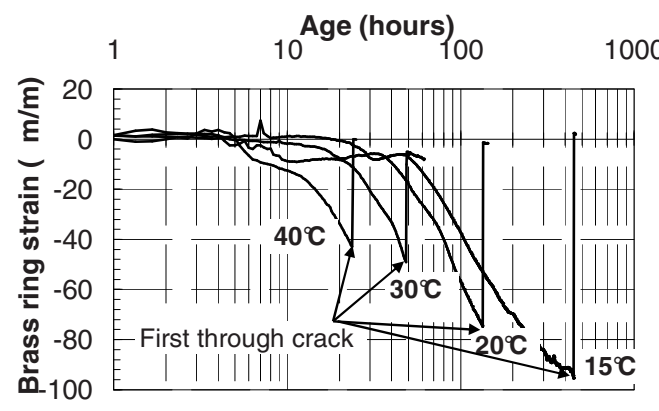

a) Typical ring test curves $(\mathrm{CEM} \mathrm{I}$ cement; $\mathrm{W} / \mathrm{C}=0.30)$

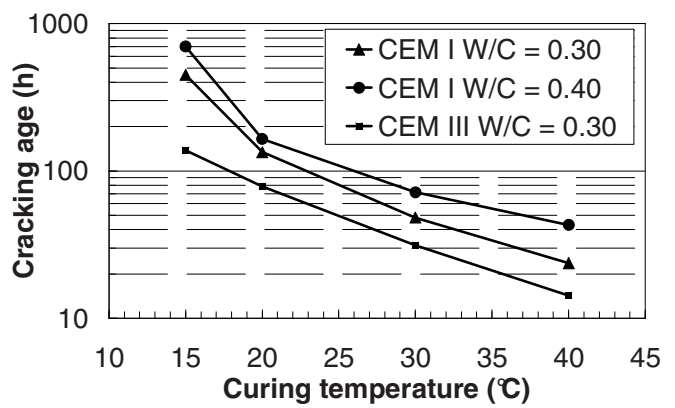

b) Cracking age of cement pastes

Fig. 8. Influence of cement paste composition and curing temperature on early- age autogenous cracking of different cement pastes. 


\section{Conclusions and further research}

From the analysis of the results obtained, the following conclusions can be drawn:

- The evolution of chemical shrinkage is largely conditioned by the type of cement used. Among the three cements used (CEM I, CEM II and CEM III), the cement containing blast furnace slag generates highest chemical strain, for a given quantity of chemically-bound water.

- The higher autogenous shrinkage of CEM III cement can be explained by higher cement fineness, higher chemical shrinkage and also lower Young's modulus at early age. Cement of type II, containing $24 \%$ of limestone filler, shows a dynamic Young's modulus closed to that of CEM III cement, but a lower autogenous shrinkage. This lower autogenous strain can be attributed to a dilution effect due to the presence of limestone filler: the higher amount of water available for cement hydration leads to lower capillary and self-desiccation phenomena.

- The presence of aggregates modifies the capacity of deformations of cement paste. This effect is related to the increase in the global stiffness of the mixture (caused by the presence of aggregates) but also, to a local restraining effect of cement paste deformations in the vicinity of aggregates, highlighting with SEM observations at the cement paste/aggregates interface.

- The study of deformations in restrained conditions enabled to quantify the acceleration effect of temperature on autogenous early-age cracking and demonstrated the greatest sensitivity of CEM III cement to the risk of premature through-cracking.

\section{References}

1. P. Acker, Comportement mécanique du béton : Apports de l'approche physicochimique (LCPC, 1988)

2. J.M. Torrenti, Comportement mécanique du béton : Bilan de six années de recherche (LCPC, 1996)

3. A. Bentur, Shrinkage 2000 (Paris, 2000)

4. NF EN 196-1 Standard, 2006

5. NF EN 196-3 Standard, 2009

6. M. Bouasker, $\mathrm{PhD}$ dissertation (University of Nantes, 2007)

7. P. Mounanga, A. Khelidj, A. Loukili, V. Baroghel-Bouny, Cem. Concr. Res. 34, 2 (2004)

8. M. Bouasker, P. Mounanga, A. Khelidj, R. Coué, Adv. Cem. Res. 20, 2 (2008)

9. A. Pertué, P. Mounanga, A. Khelidj, D. Fournol, ICEM 13 (Alexandroupolis, 2007)

10. E. Holt, PhD Dissertation (University of Washington, 2001)

11. M. Cyr, P. Lawrence, E. Ringot, Cem. Concr. Res. 36, 2 (2006)

12. P. Lura, K. van Breugel, I. Maruyama, Cem. Concr. Res. 31, 12 (2001)

13. Z. Jiang, Z. Sun, P. Wang, Cem. Concr. Res. 35, 8 (2005)

14. K.M. Lee, H.K. Lee, S.H. Lee, G.Y. Kim, Cem. Concr. Res. 36, 7 (2006)

15. S. Hanehara, H. Hirao, H. Uchikawaawa, Autoshrink' 98 (Hiroshima, 1998)

16. P. Lura, O.M. Jensen, J. Weiss, Mater. Struct. 42, 8 (2009)

17. N. Belaribi, G. Pons, B. Perrin, Cem. Concr. Res. 27, 9 (1997)

18. A. Elsharief, D. Menashi, O. Jan, Cem. Concr. Res. 33, 11 (2003)

19. V. Baroghel-Bouny, P. Mounanga, A. Khelidj, A. Loukili, N. Rafaï, Cem. Concr. Res. 36, 1 (2006) 